\title{
A Generalized Statement of Scientific Ethics Intended to Cover All Forms of Scientific Endeavor with the Primary Purpose of Protecting the Independent Researcher
}

\author{
Peter Bissonnet \\ Independent and Unaffiliated Researcher, Fusagasuga, Cundinamarca, Colombia \\ Email: peterkey1624@gmail.com
}

How to cite this paper: Bissonnet, P. (2020). A Generalized Statement of Scientific Ethics Intended to Cover All Forms of Scientific Endeavor with the Primary Purpose of Protecting the Independent Researcher. Open Journal of Philosophy, 10, 24-35. https://doi.org10.4236/ojpp.2020.101003

Received: November 11, 2019 Accepted: December 15, 2019 Published: December 18, 2019

Copyright $\odot 2020$ by author(s) and Scientific Research Publishing Inc. This work is licensed under the Creative Commons Attribution International License (CC BY 4.0).

http://creativecommons.org/licenses/by/4.0/

\begin{abstract}
The author finds that it is necessary to post a generalized statement of scientific ethics intended to cover all forms of scientific endeavor as society, government, and Science change and evolve. The author's method of research is based on 1) his own experiential interaction with publishers and universities, 2) what he sees happening politically around the world today, and 3) his own belief system, common sense, and logic on how to make Science better. Consequently, the author believes that a more stringent and specific statement of scientific ethics should be made. Plagiarism is one of the dirtiest activities in the world of Science today. It is practiced by desperate scientists and universities, both of whom desire personal aggrandizement and accolades to which they are not entitled. This practice seems to the author to be most prevalent by the larger scientific concerns against those of whom are referred to as "independent researchers". There are two research aims in this paper: 1) the main aim is to protect and alert "independent researchers" to nefarious practices being carried out and 2) the secondary aim is to suggest strongly to all scientists that the independence of Science as an "institution" is critical, before it is irretrievably swallowed up by government and the military, collectively called the State.
\end{abstract}

\section{Keywords}

Scientific Ethics, Plagiarism, Absolute Truth, Institutionalized Plagiarism, Institutionalized Segregation, Plagiaristic Searches

\section{Introduction}

The problems which need to be addressed in this paper are: 1) to alert the small 
"independent researcher" of nefarious practices intended to disenfranchise him of his basic discoveries by the larger institutions-in other words we are talking about that nasty word called plagiarism; 2) to basically declare that Science is the only beacon of truth we have in this world, notwithstanding religious concepts, and that it is very dangerous for Science to become bed-fellows with the State.

The exposition of scientific ethics changes with the times. Ethical principles in Science represent a set of morality concepts which govern how people interact with each other with respect and decency in the scientific realm. If there were no scientific principles regarding ethics, then Science would revert to a dog-eat-dog environment. The large scientific concerns would prevail over the small researchers on the principle that might-makes-right. This would have the unfortunate effect of changing the history of who made what discoveries in a time-like manner. Further, there is a danger that prize giving organizations in Science could be lulled into thinking that scientific discoveries were made by scientists at the large institutions and that small scientists, amateurs, and independent researchers (in this paper called by the common name of "independent researchers"), could be discredited and ignored. Who would stand up for these "little guys"? Scientists at the larger scientific concerns certainly would not, since they draw their paychecks from these concerns and would not place their paycheck and status in danger. Also, as previously mentioned, the independence of Science is discussed.

\section{Affirmations of Scientific Ethics}

\section{See (Carpi \& Egger, 2009) and (NewScientist, 2017) for an overview of many examples)}

1) To affirm that anyone who desires to do Science has the inalienable and absolute right to pursue scientific research regardless of race, color, sex, creed, religion, language, national origin or any other attributes which serve to distinguish human beings from one another.

2) To affirm that scientific research is conditioned upon: a) the ability of the person to talk and write the language of Science; b) the use of such language to logically pursue investigations, such investigations being built upon the scientific conclusions and experiments of the past and present; c) the communication of the results of such investigations to all other scientists by publishing.

3) To affirm not to ignore facts when presented with such facts.

4) To affirm a) not to plagiarize the scientific work of fellow scientists for purposes of self-aggrandizement, but to give credit where credit is due; b) to reject institutionalized plagiarism against the much smaller group of independent researchers (not affiliated with any institution), who are generally unable to defend their discoveries against the larger scientific institutions, where the majority of Science is carried out; c) not to create any artifice whose purpose is to limit the publishing of or to create any segregation of the works of independent researchers; d) to condemn any attempts to limit plagiaristic searches by publish- 
ing companies, where such limitations are brought about by one country against another, due to political, economic, or militaristic intrigues, the purpose of such limitation being to elevate the contributions of scientists of one country and to reject the contributions of scientists from other countries.

5) To affirm to constantly maintain high moral purpose and integrity in the conduct of scientific research; in other words, don't fake data in order to satisfy some government or political agenda.

6) To affirm to make a conscious attempt to seek truth at all times.

7) To affirm to try and maintain at all times a recognition of the differences between absolute truth and relative truth insofar as how these different concepts of truth are relevant to the self-management/self-independence of Science.

8) To affirm that scientists have the absolute right to investigate any and all avenues which they may consider as leading to any facet concerned with absolute truth.

\section{Explanatory Notes of the Above Affirmations}

The numbers in parenthesis below refer to the corresponding affirmations above.

1) Why is this affirmation necessary? Scientists are human and are subject to the whims of egotism. According to Wikipedia, egotism is defined:

"Egotism is the drive to maintain and enhance favorable views of oneself, and generally features an inflated opinion of one's personal features and importance. It often includes intellectual, physical, social and other overestimations" (Wikipedia, 2019).

If the above affirmation (1) in the list of Scientific Ethics were not stated, then we would have a situation as in ancient Egypt, where the high priests were in control of secrets of Science, and they and only they would have the right to possess such knowledge. In the modern world, government or the military would probably take the place of the high priests.

2) The inclusion of this affirmation is self-explanatory. How can you communicate in a language, if you are not proficient in the language?

3) The inclusion of this affirmation is necessary, due to the fact that scientists become welded to their theories. Many times, the presentation of new facts is ignored because they do not fit into the overall framework of their pet, favorite or current orthodox theory.

4) (a) This affirmation is necessary because, again, scientists are human and many respond to egotism. Some scientists work for decades in a particular field and never receive the "glory" which they think they deserve. This unfulfilled and artificial "Great Expectation" never arrives and so many perceive that they are "owed" something by society and so plagiarism becomes an attractive alternative. Universities are run by human beings, and so universities also respond in similar ways.

4) (b) This affirmation is necessary due to the author's personal experience with having published a paper through a certain publishing outlet. Later on, a 
person published a paper on nearly the same exact subject without giving the author credit. There was a certain European university which was involved which had ties to the publisher and to the person who published the paper. The author contacted the publisher owner and was told that other of their clientele also complained of similar treatment by this university. This is institutionalized plagiarism and apparently is quite common. It consists of various universities preying upon independent researchers, who make discoveries and are unable to defend themselves in a court of law or be taken seriously in the court of scientific public opinion. Further, scientists are deluding themselves, if they believe that there is any set of "permanent" implementations or mechanisms in place which will ensure that they will not be plagiarized. Governments, if they are desperate and have a mind to, can nullify any such implementations or mechanisms, just as easily as they can exit out of treaties (which were thought to be inviolable) with other countries.

If scientific historians recognize the theft of intellectual property or plagiarism by big universities against those scientists who are incapable of defending themselves, then this is saying to the world of scientists that it endorses institutionalized plagiarism. Institutionalized plagiarism also says to historians of mathematics and Science that big universities have the power and authority to usurp rights normally construed to such historians, and, further, that big universities have the power to change the course of history itself in determining who or what group "discovers" any concept, thus affecting and artificially determining the course of the history of mathematics and Science.

4) (c) This affirmation is already being violated by certain preprint organizations, in which a person cannot input a paper without knowing someone already on the "inside" so to speak.

Independent researchers have just as much right to work on problems of physics and mathematics as those "chosen few" who work under the auspices of the university umbrella. The author uses the phrase "chosen few" as it is an apt term to describe an institutionalized concept already imposed upon Science, and that is the concept of institutionalized segregation. Yes, that is the successful attempt to say to researchers that some scientists are acceptable to Science and there are others who are not acceptable. This institutionalized segregation finds its pregnant moment in some on-line preprint organizations, as previously mentioned. Yet if one of these unacceptable scientists makes a valuable and unexpected discovery, you can bet your life that there will be all sorts of nefarious attempts by the "chosen few", and the universities which they are affiliated with, to find a way to institutionally plagiarize such idea(s).

4) (d) This affirmation is necessary due to the present condition in world affairs of a stand-off, so to speak, between the East and the West in social, economic, and militaristic matters. It is only common sense to expect that a scientific stand-off will probably occur as well, and plagiaristic searches by publishing companies might very well be a "weapon" to use. 
5) This affirmation is necessary, for example, in the global realm when international treaties are entered into by countries regarding subjects which are based upon scientific data. If the scientific data has been mishandled or purposely distorted then it could lead to public disagreements and even to a breakdown of treaties if countries should begin to withdraw from such treaties. Further, it leads to accusations of shameful practices against the scientists involved. Manipulation of scientific data on less than the global realm is equally reprehensible, when practiced according to some pre-defined personal agenda.

6) This affirmation is self-evident or incontrovertible, as the pursuit of truth and the determination of truth is everything that a scientist is supposed to stand for.

7) (a) Absolute and Relative Truth

Truths, such as the Fermi constant, the Planck constant and the speed of light are valid from planet to planet in our universe and can be called Absolute Truths, which are assumed not to change with time. Relative truth, for example, may include studies regarding a population of animals here on earth, but which has no significance to other planets, where such animals do not exist. If there are multiple universes outside our own universe, then it is highly likely that each such universe has its own set of Absolute Truths, different from our own. Such universes would be "forbidden" to interact with each other, which would contradict the concept of Absolute Truths within each universe. This forbiddance to interact would be an overriding law or governance concerning the total of these universes. If there is one overriding law or governance, then more than likely there is more than one. Then we would be faced with the concept of Absolute Absolutism which would be necessary to govern the total set of universes taken as a whole, and therefore individually as well.

From the previous paragraph, we can thus deduce that there are at least two types of Absolute Truth; namely, Steady State Absolute Truths (which do not change with time) and Transient Absolute Truths (which do change with time) within each universe. The former would include the Fermi constant, the Planck constant and the speed of light, as well as a myriad of others. The latter is a whole new animal, so to speak. These Transient Absolute Truths would show up occasionally and sporadically, whenever the agency called Absolute Absolutism exercises its governance of the set of universes taken as a whole, as well as individually. Also, if it turns out that any constant taken as an Absolute Truth does change with time, then it would automatically be relegated to the set of Transient Absolute Truths. Further, there are two types of Steady State Absolute Truths and two types of Transient Absolute Truths: these two types for each are Observable and Unobservable:

Observable Steady State Absolute Truths-e.g. the constants of nature which are constant from planet to planet within each universe and do not change with time or place.

Unobservable Steady State Absolute Truths-e.g. the agency of Absolute 
Absolutism.

Observable Transient Absolute Truths-e.g. the occasional and sporadic traces within each universe of the governance of that universe by the agency of Absolute Absolutism which lie within the observable realm. Also, constants of nature which change with time. An example would be true miracles and occasional glimpses of paranormal phenomena.

Unobservable Transient Absolute Truths-e.g. the occasional and sporadic traces within each universe of the governance of that universe by the agency of Absolute Absolutism which lie outside of the observable realm. Examples would be the soul and spirit (these are different; consider that a set of flower petals represent the soul and the stem represents the spirit. The stem goes down to the life-giving soil, and the spirit goes back to a life-giving Creator Spirit.) Another example would be a "Thought Adjuster" as described in the Urantia Book.

The self-management/self-independence of Science is a reflection of how each scientist treats each and every project that he is involved with. Science is managed well when the ethics of each scientist is incontrovertible. The reader may offer a dispute by saying that projects of scientific research, such as atomic bombs, can be used to kill thousands of people, thus showing that Science is not well managed. On the surface, this appears to be true, but this objection is easily refuted by recognizing that there is another governance imposed upon our universe by the agency previously referred to as Absolute Absolutism, and that is the rule referred to as Dualism by the author.

7) (b) Dualism

Dualism is the author's concept that everything or nearly everything in the universe has a potential for either good or bad or can be used for good or bad.

i) Nuclear energy can be used for atom and hydrogen bombs or it can be used to generate electricity, helpful to human civilization.

ii) A flower pot can be used to grow your favorite beautiful bulb or it can be dropped from the top of a sky scraper to an unfortunate head below.

iii) Drinking water can save your life if you are stranded in the desert, but too much water in your body can enlarge the blood vessels and other cellular tissue and make the heart valves pump with a squishing sound, artificially simulating a hole in the heart. The heart valves try to close on a heart overly full of water, and it is like trying to squeeze water in your hand, the water shoots out giving a wrong analysis by the Doppler heart machine and a wrong diagnosis by the physician.

iv) Electricity can burn a hurtful wart or cancer from your hand or it can electrocute you.

v) All electrical appliances can be used for performing some useful function, but they all have the potential of overheating or breaking and thus causing some sort of damage, from ruining a recipe to burning your house down. Even cellular phone batteries have the potential of exploding. The cellular phone can be used 
to call an ambulance or be used in child pornography.

vi) A car can transport you to the hospital saving your life or it can be used by a terrorist to smash into a group of people. Remove the wheels from the car so that it cannot be used by terrorists, and you also remove the ability of the car to transport to the hospital. In other words, you cannot remove the bad without removing the good as well. Somewhat similar to quantum phenomena, you cannot confine a particle without affecting its momentum and vice-versa.

vii) Human beings themselves can be good or bad, as a result of their inherent free will.

viii) A pet dog can be a joyful pleasure when you are the ideal owner. When this same dog is placed under a cruel master, you have a paranoid and vicious animal.

ix) A book can be used to teach you something, or it can be used to bash someone over the head.

x) A dam can be used to generate electricity or to provide water for irrigation, but if the dam busts, then look out!

xi) "Only one ethical principle-duty to society-applies to the scientific inquiry by asking whether the research benefits society" (Weinbaum, Landree, Blumenthal, Piquado, \& Gutierrez, 2019). According to this quote, Science is supposed to ignore all inquiries that do not benefit society, in other words, those things which are good for society, when, in actuality, under the concept of Dualism, this is impossible. This quote is purely for advertising purposes, as it is intended to have the same quelling effect upon the masses of society just as Rome used "bread and circuses" to keep their populations under control.

To make a statement like this is ridiculous, because it implies that Science should search for only those ideas and projects which only have a "good" side. However, dear reader, consider that the philosophy of today's scientists is mostly mechanistic (Sheldrake, 2012) a philosophy in which they deny anything or "anyone" existing in the supernatural world, especially a Creator, who interacts with our universe in positive ways only. This would be the only way that they could find something solely good and not bad, but their mechanistic philosophy precludes what they are searching for! Society benefits from scientific inquiry as a consequence not as a goal! As for the individuals of society, their philosophy is mechanistic as well, seeking only those benefits that society can bestow such as luxury, wealth and possessions and having a side effect of producing people of low morality. From this morass of luxury, wealth, possessions, and low morality, we also select our political leaders ... think about that!

Let's not kid ourselves. A duty to society is synonymous with a duty to the State, which governs the society. The State is the major source of fake news and false-flag attacks, and Science is supposed to be subservient to this mockery? Give me a break, please! Many countries around the world today and in past months are in political turmoil and violence by their populations, including those in Europe, South America and the Far East. These populations are not rebelling against Science, but against the State. It is the State which owes a duty to 
society, not Science. Science must be independent of the State and therefore a beacon of truth to society and the State in terms of achievement, dialogue and preservation of truths from the past and present in order to ensure that there are no more "Julius Caesars" with intents of burning down "Alexandrian libraries" and destroying the accumulated knowledge of centuries. You, the reader, don't think that this can happen? Some militaries around the world are itching to try out the new versions of atomic bombs which are limited to smaller ranges of destruction. How many new "Julius Caesars" are there out there with such grandiose plans? If you, the reader, know, please don't tell me!

From (Cossins, 2017), we see that population controls are being discussed or considered. If Rand Corporation found an ethical principle involving a duty to society by Science, then does the duty to society involve controlling populations? How would this be accomplished? Black ops helicopters or black trucks, in the middle of the night, carrying powerful gamma ray sources in order to sterilize whole neighborhoods, or would this be done by shots or pills or sugar cubes like was dished out to the populace in order to eliminate polio, or would it be done by high taxation on families for having children, or would it be done by powerful microwave transmitters from satellites in space in which whole countries could be sterilized-and, by the way, which neighborhoods/countries would be chosen-poor? Immigrant? Racially inferior? DO NOT WORRY DEAR READER! The author is only trying to put two points across, and that is the contradictions involved in considering "duty to society" and also that the phrase "duty to society" also fits the Dualism model, in that it has a good side and a bad side. Further, don't talk to me about future duties to society by acting against the present society. Example: what if you have a family member that is an idiot? What do you do? Take him to a cliff and push him over like the caveman used to do, so he would not be a burden on society (i.e. the State) in the future-siphoning off desperately needed funds that the State needs to fight wars over oil, water, farmland, mineral resources, etc. How many readers out there actually believe that society can dictate any policy to the State? Don't talk to me about electing people to power in order to change things at the level of the State. The State has its own internal methods of discipling and dealing with anyone out to change the agenda of the State. That's exactly why there are many places around the world in political turmoil as this paper is being written.

8) This affirmation is crucial, because it not only has ramifications for the independent researcher, but for the regular scientist as well. If any government and/or military, i.e. the State, can pre-determine avenues of investigation in Science on those scientists which do not work for the government or military-when such investigations should be left up to the particular independent scientist interested in doing research-then this places all researchers, independent or otherwise, in precarious and untenable positions and makes a mockery of Science, by inhibiting creativity-the main cornerstone of Science. Oh, and by the way, I challenge any scientist to stand up and say publicly that throughout the entire history of Science that no so-called "amateur" or "independent re- 
searcher" has ever made a contribution, major or otherwise, to Science, which of course includes mathematics.

\section{Conclusion}

One of the early films to challenge the independence of Science is the film THE COSMIC MAN (The Cosmic Man, 1959) in which scientist Karl Sorenson (played by Bruce Bennet) says to Col. Matthews (played by Paul Langton) "Since Hiroshima, Science and the military are one." The author considers that this is a crass statement, not at all well thought out. In a way, this statement is true, as the military in World War II had to recruit scientists outside the military in order to solve some of the major problems in fighting the war, such as radar, sonar, and bombsights, but this still doesn't mean that Science and the military are one and the same. If I ask the local mechanic to fix my car, does that mean that his family and mine are eternal bosom buddies forever? Come one, use common sense; the best way to fight illogical arguments is to use counter-examples! If you think that this statement by Sorenson is true, consider the following article from the New York Times dated November 7, 2019 in which the FSB (formerly the KGB) in Russia raided the Lebedev Physics Institute in Moscow, which has produced seven Nobel Prize winners (Higgins \& Kishkovsky, 2019). Scientists and universities had better think very carefully about cozying up to government and the military and whether such things can happen in the so-called "western democratic societies", considering that the overall trend in governments, all over the world, in these modern times is to emphasize and exercise control over the masses in order to preserve the agenda of the State. Needless to say, this control would also apply to all scientists-those acceptable and to those not acceptable!

The pressures of today's world are heavy upon scientists and universities. Just look at the following quote (Sharma, 2015):

The scientific activity has been competitive all along. However, during the last few decades, there has been an explosion of knowledge and the advent of digital age. We can access any information including the publications of competitors with just a "click". The evaluation parameters have evolved a lot and are based on impact factors, $h$-index and citations. Overall, it looks like a rat-race and there is a sense of publish or perish. There is a cut throat competition for publishing in journals with maximum visibility and winning grants. There is a general feeling that the scientific community is under a lot of pressure for fulfilling the norms and criteria for upward growth and even retention of the positions held. In the backdrop of this scenario, the noble profession of scientific research and academics has been marred by the temptation to falsify and fabricate data, plagiarism and even sabotage.

The independent researcher should take care and take note. The handwriting is on the wall! Your discoveries may be eaten by the sharks infesting the waters of Science. 
The author disdains having to again rain on someone else's parade, but just as with the previously mentioned concept of "duty to society", we must now deal with the concept of "accountable to the public" (Resnik, 2015).

... many of the ethical norms help to ensure that researchers can be held accountable to the public. For instance, federal policies on research misconduct, conflicts of interest, the human subjects protections, and animal care and use are necessary in order to make sure that researchers who are funded by public money can be held accountable to the public.

Again, as with "duty to society" this is a political statement designed to appease the masses and, as with "duty to society", any accountability to the public is synonymous with accountability to the State; such concept again attacks the independence of Science. As mentioned before, the populations of various countries and cities around the world today and over the past few months are not rebelling against Science, they are rebelling against the State. This myopic mindset of "accountable to the public" ignores the fact that the State receives money from the public, and it is the State that owes accountability to the public. When Science follows the path of absolute truth, as witnessed by the activities of each and every scientist that adheres to affirmations of ethics such as those above, then Science is altogether of moral purpose and totally consistent with society.

Affirmations 5, 6, 7 and 8 are inter-related. The high moral precepts of each scientist are separately and integrally important to the self-management/selfindependence of Science. At no time should a scientist play as if he/she were a god of some type. Is there a difference between good Science and bad Science? Yes, but only in the lineal execution, e.g. fudging data to conform to a pre-established set of beliefs/agendas, instead of letting the cards fall where they may or throwing away or disregarding data as irrelevant which does not lie on the line where most of the other data resides. Is Science good or bad? This is different from good Science and bad Science. This has nothing to do with execution, but with elements of morality. Again, this has to do with how each scientist conducts himself/herself relative to the project being worked upon. For example, if a scientist purposely tries to create a being from Greek mythology, such as a centaur-half man and half horse, this would cause most people, scientists and non-scientists alike, to cringe in horror. The creation of the Frankenstein monster would also have a similar effect. Such projects would be morally reprehensible.

Would the above affirmations cause Science to become better? Yes, of course. Better at protecting independent researchers by leveling the playing field; better at maintaining the independence of Science from the sticky hands of the State, which seeks to dominate and control all things. By the way, it just occurred to this author that the State does everything it can to make itself look like some kind of god on earth. The Roman empire knew this, that's why they always put a slave in the chariot of a Roman hero returning from the Legion's wars, such person whispering in the ear of the hero "Remember you are a mortal". 
This is a perfect example of how the egotism of human beings works, and especially those of ivory tower scientists. Science is a human endeavor like marriage. Both can become better, but all participants have to put in the necessary work and effort.

Many of you after having read this paper will still insist that Science has a duty to society due to the fact that Science receives its major funding from society via the State. Again, this is sheer non-sense! Please remember, dear reader, that each and every State works on the same principle, and that is fear, fear of losing sovereignty, fear of losing hegemony, fear of losing the competitive edge, fear that some other state is greater economically or militarily, fear of running out of water, farmland, mineral resources, fear of the brain drain, fear that other states will make a major break-through in Science, fear of currency collapse, fear of war, fear of peace, etc. Society and the state are and will be compelled to fund Science, whether they like it or not, since a stagnant Science is a sure road to disaster.

In closing, plagiarists are fools! The good news is that even Science needs fools according to some philosophy the author heard somewhere, "without fools we could never know wisdom".

\section{Acknowledgements}

The author wishes to thank the reviewers for their important comments in making this a much better paper.

\section{Conflicts of Interest}

The authors declare no conflicts of interest regarding the publication of this paper.

\section{References}

Carpi, A., \& Egger A. E. (2009). Scientific Ethics. Visionlearning Vol. POS-2 (5). https://www.visionlearning.com/en/library/Process-of-Science/49/Scientific-Ethics/161

Cossins, D. (2017). The Ethics Issue: Should We Impose Population Controls? NewScientist-The Daily Newsletter, 5 July, 2017.

https://www.newscientist.com/article/mg23531331-300-the-ethics-issue-should-we-im pose-population-controls/

Futura Productions (1959). The Cosmic Man. https://www.imdb.com/title/tt0052702/

Higgins, A., \& Kishkovsky, S. (2019). Russia Raided a Physics Institute-Kremlin Watchers Are Mystified. New York Times, 7 November, 2019.

https://www.nytimes.com/2019/11/07/world/europe/russia-raid-physics-institute.html

NewScientist (2017). The Daily Newsletter.

https://www.newscientist.com/round-up/ethics-issue/

Resnik, D. B. (2015). What is Ethics in Research \& Why is it Important? National Institute of Environmental Health Sciences.

https://www.niehs.nih.gov/research/resources/bioethics/whatis/index.cfm

Sharma, O. P. (2015). Ethics in Science. Indian Journal of Microbiology, 55, 341-344. 
https://www.ncbi.nlm.nih.gov/pmc/articles/PMC4456506/ https://doi.org/10.1007/s12088-015-0532-x

Sheldrake, R. (2012). The Scientific Creed. The Science Delusion: Freeing the Spirit of Enquiry. Coronet Publications. http://blogspersonals.ara.cat/desdelparadis/2018/11/15/the-scientific-creed/

Weinbaum, C., Landree, E., Blumenthal, M. S., Piquado, T., \& Gutierrez, C. I. (2019). Ethics in Scientific Research: An Examination of Ethical Principles and Emerging Topics. Rand Corporation Publication.

https://www.rand.org/pubs/research_reports/RR2912.html https://doi.org/10.7249/RR2912

Wikipedia, The Free Encyclopedia (2019). Egotism. Published by Wikipedia Foundation, Inc. (NPO). https://en.wikipedia.org/wiki/Egotism 